\title{
Manufacture of Partially Biodegradable Composite Materials Based on PLA-Tires Powder: Process and Characterization
}

\author{
Carlos Rolando Rios-Soberanis, ${ }^{1}$ Shuchi Wakayama, ${ }^{2}$ Takenobo Sakai, ${ }^{2}$ \\ José de los Ángeles Rodriguez-Laviada, ${ }^{1}$ and Emilio Pérez-Pacheco ${ }^{3}$ \\ ${ }^{1}$ Centro de Investigación Científica de Yucatán, Unidad de Materiales, Calle 43, No. 130, Colonia Chuburná de Hidalgo, \\ CP 97200 Mérida, YUC, Mexico \\ ${ }^{2}$ Tokyo Metropolitan University, Mechanical Engineering Department, 1-1 Minami-Ohsawa, Hachioji-shi, Tokyo 192-0397, Japan \\ ${ }^{3}$ Instituto Tecnológico Superior de Calkiní en el Estado de Campeche, Avenida Ah Canul SN por Carretera Federal, \\ CP 24900 Calkiní, CAM, Mexico
}

Correspondence should be addressed to Emilio Pérez-Pacheco; eperez@itescam.edu.mx

Received 21 February 2013; Accepted 16 April 2013

Academic Editor: Osman Gencel

Copyright (C) 2013 Carlos Rolando Rios-Soberanis et al. This is an open access article distributed under the Creative Commons Attribution License, which permits unrestricted use, distribution, and reproduction in any medium, provided the original work is properly cited.

\begin{abstract}
This research work focuses on the processability and mechanical characterization of blends of polylactic acid (PLA) and tire (elastomeric part). Wasted tires used as filler in the PLA matrix were reduced by two different processes (thermal shock and pyrolysis) in order to acquire the solid residuals in powder to be characterized and compared. Elastomeric solids obtained from scraped tires were used as filler in the PLA matrix and mixed in a Brabender $60 \mathrm{cc}$ mixer at different concentrations ranging from $0 \%$ to $60 \%$ of filler volume fraction. The blend was laminated, and then samples were obtained in order to undertake mechanical properties at tension and Izod impact tests. A fully detailed analysis on the solid powders by Differential Scanning Calorimeter (DSC), thermogravimetric analysis (TGA), infrared analysis (IR), and scanning electron microscopy analysis (SEM) identified them as a rich source of carbon. Blends were characterized thermally and mechanically showing a direct effect due to the tire nature (thermoset rubber) and concentration. Fracture mechanisms were also identified.
\end{abstract}

\section{Introduction}

In recent years, there has been widespread interest in the manufacture of products from recycled materials. Among the advantages of doing this is the fact that material recycling makes the technology more economically and environmentally attractive [1]. Particularly among the waste materials in the advancement of civilization, waste tires are a major concern, because the amount of waste tires is increasing more and more due to the increasing demand for tires, and because of their short lifetime, it is therefore necessary to develop methods for recycling waste tires.

A number of approaches have been proposed to make use of the large amount of waste rubber; one of them is like biopolymer. Biopolymers are expensive and have either property or processing limitations [2]. Most durable bioresins available in the markets are based on PLA. Biopolymers are made from PLA blended with polymers like polycarbonate (PC), polypropylene (PP), acrylonitrile butadiene styrene (ABS), high impact polystyrene (HIPS), polyethylene terephthalate (PET), and poly(methyl methacrylate) (PMMA). Fillers, fibers, and additives are also added to the blends to prevent degradability, increase processability, reduce brittleness and speed crystallization. In order to overcome disadvantages, such as poor mechanical properties of polymers from renewable resources, or to offset the high price of synthetic biodegradable polymers, various blends and composites have been developed over the last decade [3-5]. Until the last decade, the main uses of PLA have been limited to medical applications such as implant devices, tissue scaffolds, and internal sutures because of its high cost, low availability and limited molecular weight [6]. However, recently PLA has been widely used in new developments in composite materials technology, since it has been viewed as a promising 
material to reduce the societal solid waste disposal problem [7]. Blends of PLA with various nonbiodegradable polymers have been also investigated [8-10]. Some of these blends were found to be immiscible resulting in fairly poor mechanical properties. Polymer blends containing biodegradable and a nonbiodegradable components have received much interest because of the ease with which their physical properties and degradation characteristics can be tailored. On the other hand, recycling of rubber tires is not possible by simply melting and reshaping them due to the thermosetting nature of the molecular structure: the crosslinking. Spent tyres, however, comprise valuable material that could be recycled if a proper technique can be developed as it has been demonstrated [11-13]. Just like most of organic compounds, tires decompose with heat by pyrolysis that consists in the decomposition of the organic part by heating $\left(\right.$ about $400^{\circ} \mathrm{C}$ ) in absence of oxygen [14]. In this process, the type and composition of the final products depend on the properties of the organic material, the temperature, pressure of operation, time of the applied method, and the type of gaseous ambient (Ar, $\mathrm{N}_{2}$, etc.). Another consequence is that the recovered carbon black is physically different from the original one used as filler in the tires manufacturing. Such dissimilitude is directly related to morphology and structure as well as the particle size and distribution. The powder tire was obtained from scrapping the elastomeric surface of the tire in small flake-like particles (Figure 1).

The scraped elastomeric material is considered as waste, and there is not a specific final use for it, and if it is wrongly disposed can cause contamination. Every week, hundreds of kilograms of such material are produced in flake-like forms and smaller particles that could be used as filler in PLA matrix composites. The aim of this work was to investigate the manufacture and mechanical characterization of PLAmatrix-based composites filled with different contents of wasted tire flakes. One advantage of the elastomeric fillers is that they can be easily dispersed in thermoplastic polymers.

\section{Materials}

The material matrix studied is based on a commercially available Poly(lactic acid) polymer 2002D (Table 1). The tire powder was recollected from local companies dedicated to repair old tire with several damage on its surface.

\section{Experimental Procedures}

Two processes were carried out in order to obtain solid residues from tire to characterize them. The first one consisted in a pyrolytic process which applies indirect heat in an environment free of flame and oxygen. Several pieces of scraped tire were placed in crucibles and then sited in a furnace at $700^{\circ} \mathrm{C}$ for $1 \mathrm{hr}$ in the presence of nitrogen $\left(\mathrm{N}_{2}\right)$ atmosphere, and after this period of time, the crucibles were cooled down to room temperature and the carbonized samples were manually pulverized with a pestle and mortar. The second one was by thermal shock caused by the rapid change in extreme temperatures. Again, elastomeric pieces in

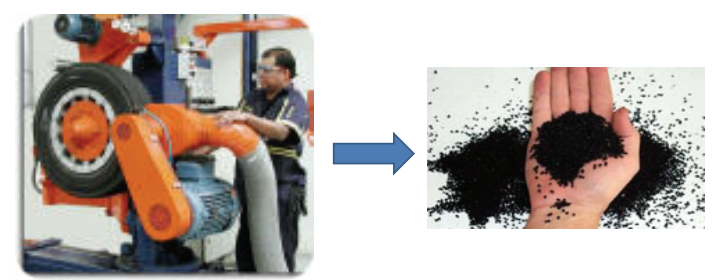

FIGURE 1: Obtaining of flake-like particles from wasted tires.

TABLE 1: Physical properties of Poly(lactic acid) polymer.

\begin{tabular}{lc}
\hline Physical properties & Poly(lactic acid) polymer \\
\hline Specific gravity & 1.25 \\
Melt index, g/10 $\min \left(190^{\circ} \mathrm{C} / 2.16 \mathrm{~K}\right)$ & $4-8$ \\
Clarity & Transparent \\
\hline
\end{tabular}

crucibles were heated in the furnace, this time at $400^{\circ} \mathrm{C}$ during $10 \mathrm{~min}$. After this brief period of time, the samples were immediately immersed in liquid nitrogen $(125 \mathrm{~mL})$. After the vaporization of $\mathrm{N}_{2}$, the residue was manually pulverized. Thermal shock was analyzed at $400^{\circ} \mathrm{C}$, because at higher temperature, the tire rubber initiates full decomposition. It was found that $10 \mathrm{~min}$ in the furnace were enough to ensure the breakage of the bonds to obtain a powder residue. Experimental diagram is shown in Figure 2. PLA/tire blends were made in concentrations from $100 / 0 \%$ to $40 / 60 \%$. PLA, used as matrix, was placed in an oven at $60^{\circ} \mathrm{C}$ during $4 \mathrm{hrs}$ previous to mixing in order to eliminate humidity due to the high hydrophilic character of PLA. Scrap tire was sieved to get a uniform size of particles around $2 \mathrm{~mm}$.

3.1. Fourier Transform Infrared (FTIR). The FTIR spectroscopy analyses were performed on all powder samples in order to characterize qualitatively the organic compounds of the solids by using transmission technique. The specimens were prepared by grinding the solid powder residue with $200 \mathrm{mg}$ potassium bromide $(\mathrm{KBr})$ powder and then pressing the mixture into a tablet. The FTIR spectrum of the powder complexes was measured at room temperature with a Thermo Nicolet (Nexus 670-FTIR) spectrometer in a spectral range of 4000 to $400 \mathrm{~cm}^{-1}$.

3.2. Thermal Analysis. These analyses were carried out to understand the thermal behavior under degradation when samples are heated to high temperatures. A Perkin-Elmer TGA-7 thermogravimetric analyzer (TGA) was used to investigate the thermal stability of the elastomeric section of the tire and the PLA/tire blends within a temperature range from 30 to $800^{\circ} \mathrm{C}$ in a nitrogen atmosphere analyzed at a heating rate of $10^{\circ} \mathrm{C} / \mathrm{min}$. DSC was achieved in a DSC-7 Perkin Elmer, with about $7 \mathrm{mg}$ samples of rubber tire, and each concentration blends at a range of $40-200^{\circ} \mathrm{C}$ and heat rate of $2^{\circ} \mathrm{C} / \mathrm{min}$. A second run was done to observe the thermal event of crystallization. 


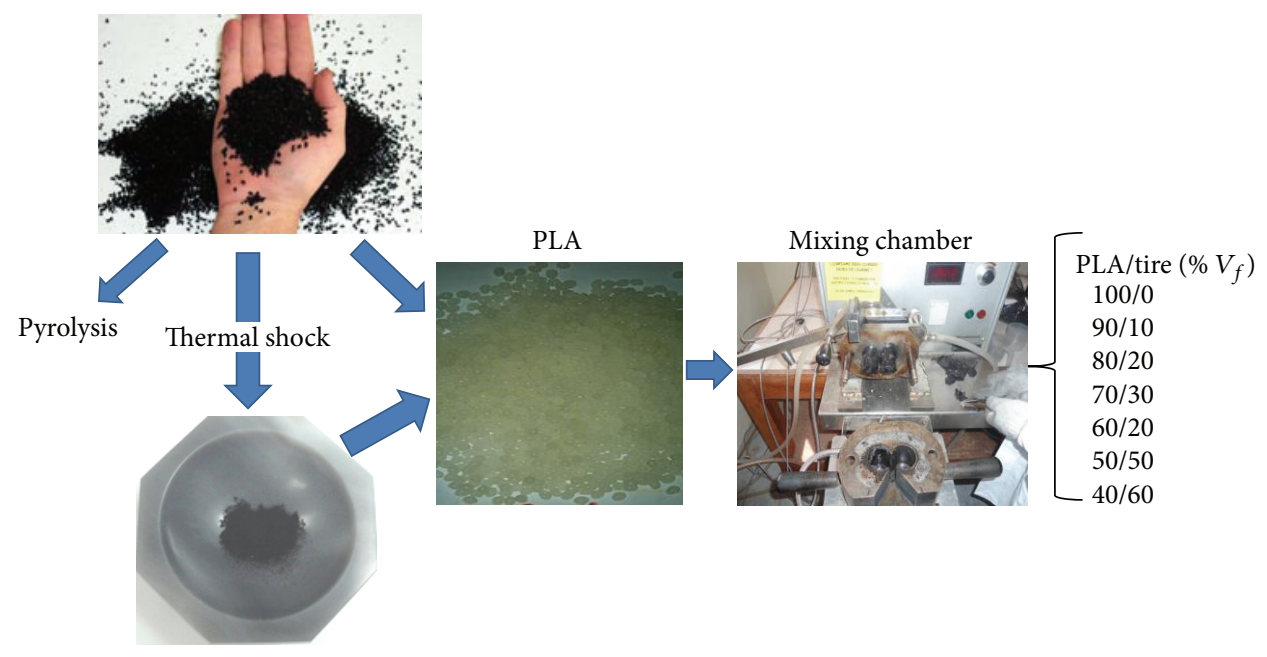

FIGURE 2: Experimental diagram.

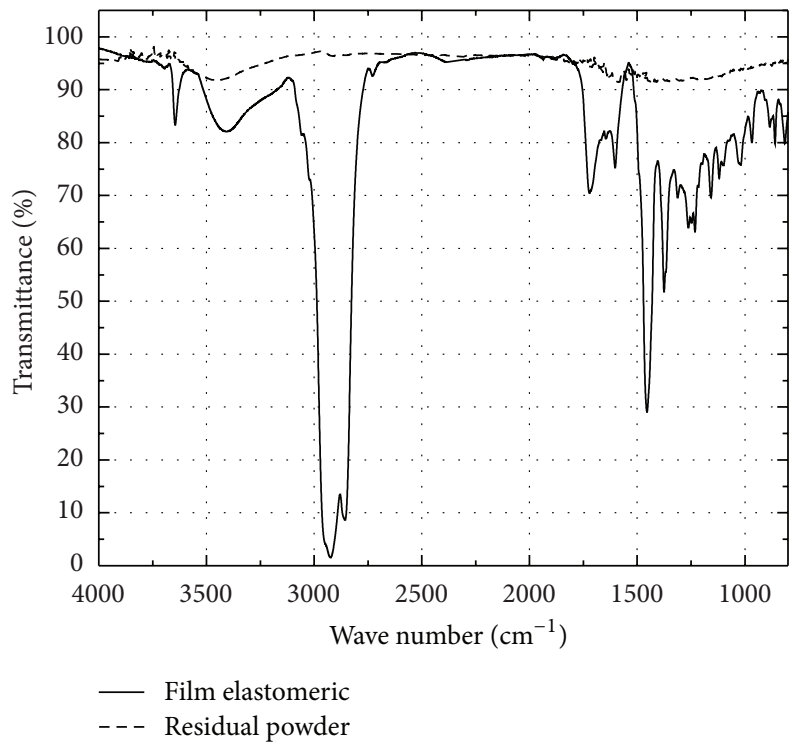

FIGURE 3: FTIR spectrum of the film obtained after extraction and the solid residue.

3.3. Particle Size and Distribution. A Coulter LS100 equipment capable of measuring particle sizes between 0.1 y $900 \mu$ with ultrasonic sound was used to determine the particle sizes and distribution of the residual powder.

3.4. Scanning Electron Microscopy (SEM). Microscopic analysis was performed on the powder in order to examine the morphology of the particles. A small amount of the uncoated powder pellets was mounted on a metallic slide, and the examination was performed with a scanning electron microscopy JEOL JSM 6360 LV electron probe microanalyzer at $15 \mathrm{kV}$ in low vacuum. Fractured surfaces of samples after rupture in tension mode were also scanned.
3.5. Mechanical Properties. The mechanical properties for tensile loadings were determinate according to ASTM D88212 standard [15]. A Shimadzu Universal testing machine, model AG-I equipped with a $5 \mathrm{kN}$ load cell and a crosshead speed of $0.5 \mathrm{~mm} / \mathrm{min}$ was used.

The impact test was carried out by Izod with al Joule hammer. The Izod notched impact strength was determined from specimens measuring $63.5 \times 12.7 \times 4 \mathrm{~mm}$ using an unnotched Izod impact instrument according to ASTM D256-10 [16].

\section{Results and Discussion}

4.1. Solid Powder Residue Characterization. According to FTIR (Figure 3) analyses, it was found that for pyrolyzed samples organic bands do not appear, because at high temperature, tires suffer a complete depolymerization; therefore organic compounds are eliminated, and the remaining are mainly inorganic compounds.

On the one hand, solid powder obtained by thermal shock process was purified with tetrahydrofuran (THF) in order to carry out an extraction of possible organic residuals. The extracted liquid was taken to evaporation. The residual solution developed a yellow film of an elastomeric appearance; therefore, the powder and the film were both characterized separately by FTIR. Figure 3 represents both spectrums where it is possible to observe that the solid residue, after the extraction, exhibits an identical pattern to that found in samples treated by pyrolysis at $750^{\circ} \mathrm{C}$ with almost no signals for organic compounds. On the other hand, the spectrum of the film is similar to that displayed by isoprene with bands corresponding to the vibrations of the group $-\mathrm{CH}_{2}-$ at $2924,2856,1455$, and $1375 \mathrm{~cm}^{-1}$, as well as vibration stretching of polyisoprene groups $\mathrm{C}=\mathrm{C}$ - and $-\mathrm{CH}$ at 1644 and $813 \mathrm{~cm}^{-1}$, respectively. The bands of lesser intensity to these correspond to signals of other compounds and butadiene-styrene residues. This result implies that a tire 


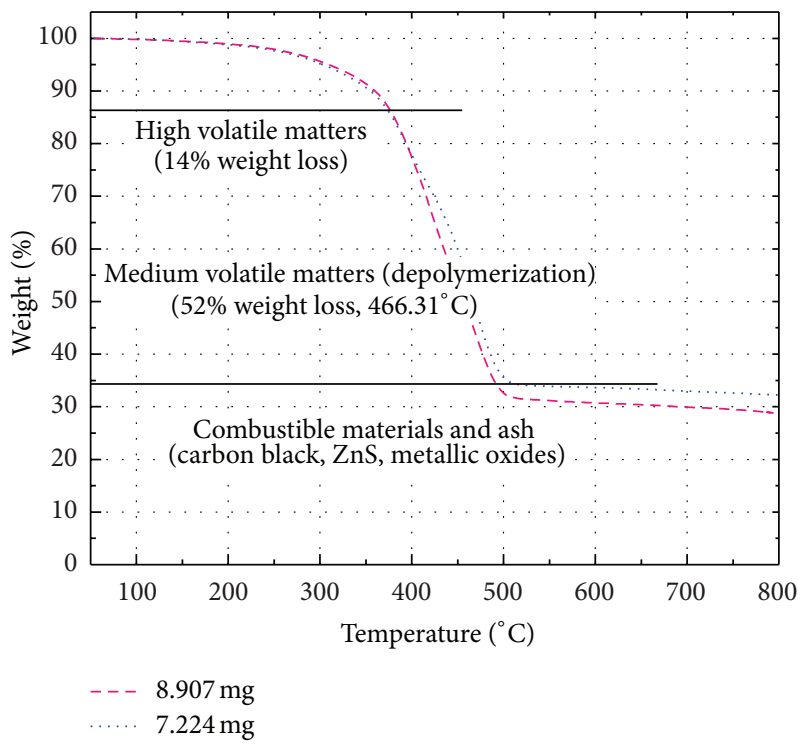

FIgURE 4: The TGA thermogram of the elastomeric part of the tire.

treated with pyrolysis followed by thermal shock avoids total degradation of the polymeric chain breaking only the sulphur bonds [17].

Thermal analysis curves of the elastomeric part of the wasted tire used in this study for a heating rate of $10^{\circ} \mathrm{C} / \mathrm{min}$ are shown in Figure 4. The thermogram shows different regions for the whole temperature range between 30 and $800^{\circ} \mathrm{C}$. These differences are the consequence of the degradation of each major constituent of rubber tires, such as natural rubber, butadiene rubber, styrene-butadiene rubber, as well as minor constituents such as oil, plasticizers, additives and moisture. In the temperature range between 80 and $350^{\circ} \mathrm{C}$ all the minor constituents are lost, as they are normally volatile materials such as low molecular weight oligomers, plasticizers, emulsifications, oils and waxes, and antioxidants. The degradation process of major constituents or their combinations occurs between 340 and $550^{\circ} \mathrm{C}$. It was previously indicated that the maximum mass loss of styrene-butadiene rubber occurs at 350 and $500^{\circ} \mathrm{C}$, maximum degradation of natural rubber at $373^{\circ} \mathrm{C}$, and for butadiene rubber at 372 and $460^{\circ} \mathrm{C}$. Finally, in the last degradation phase, above $500^{\circ} \mathrm{C}$ only about $34 \%$ of the original weight of the sample is left, corresponding to decomposition products mainly containing $\mathrm{Zn}$ and carbon atoms such as oxidized no-volatile materials, carbon black, and graphite $[18,19]$. However, in the case of rubber combinations like those used in tires, it is observed that the mass loss for each peak in the thermogram curves is dependent on the composition of the mixture. In spite of the relative homogeneity of the scrap tire used in this work, different compositions as a function of the relative amount of each elastomer are observed. We obtained similar values to those reported by Stefani et al. for temperatures and mass losses (for the same heating rates), indicating that the analyzed tire rubber has a similar composition [18].

In order to examine the uniformity or disparity in the dimensions of the solid powder obtained by two different

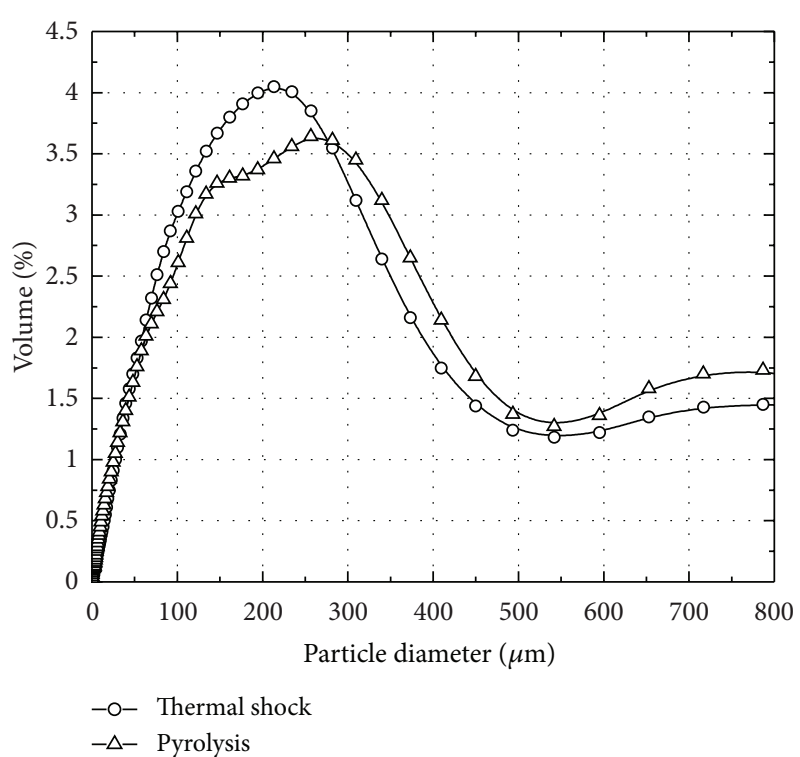

FIgURe 5: Distribution of the particle size.

processes, distribution of the particle size was studied. The results are presented in Figure 5 where the curves for pyrolysis process are compared to the curve acquired for thermal shock process. It is possible to observe the similarity in the two curves that initiate with an exponential augmentation for small particle sizes from 0 to about $180 \mu \mathrm{m}$ then a maximum appears at about 210 and $250 \mu \mathrm{m}$. Finally, the curves go down towards stabilization at about $600 \mu \mathrm{m}$ and continue to low levels of bigger particles. Invariably the particle sizes in any process are identical; this could be attributed to the manual pulverization with a pestle and mortar by using the same conditions such as pressure force and time for powdering the solids obtained.

Scanning electron microscope was used to examine the appearance of the solid powder obtained from solid reduced by pyrolysis and thermal shock, respectively (see Figure 6), where the difference in the surface area is noticeable.

Thermal shock particles (Figure 6(b)) seem to be covered by a "whitened" rubber surface due to the remaining organic residue (elastomer) as proved before by FTIR analysis. This rubber keeps the particles of the residue united originating the shape observed in the granules. Additionally, the granules size is in agreement with the information obtained by the distribution of the particle size. It was found a similarity in the granules dimensions regardless the process used to obtain the powder. However, particles obtained by thermal shock process exhibited lower amount of large solids.

4.2. PLA/Tire Material Characterization. Thermal analyses (DSC and TGA) are presented in Figure 7 where three thermal events $\left(T_{g}, T_{c}\right.$, and $\left.T_{m}\right)$ are observed. As seen in Figure 7(a), glass transition $\left(T_{g}\right)$ occurred around 55$59^{\circ} \mathrm{C}$ for all samples corresponding to PLA, while melting $\left(T_{m}\right)$ occurred with two endothermic peaks. A multiple melting behavior is a common phenomenon observed in 


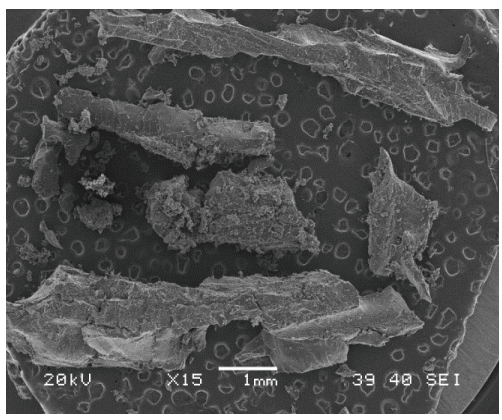

(a)

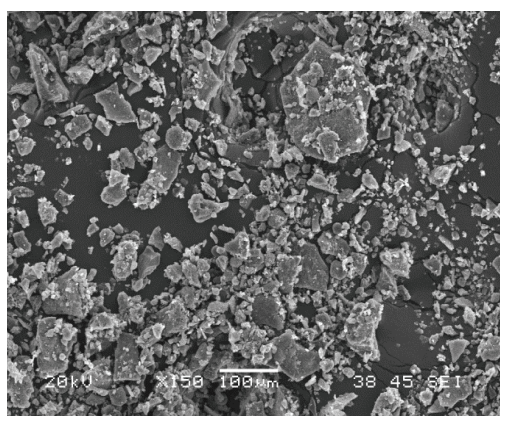

(b)

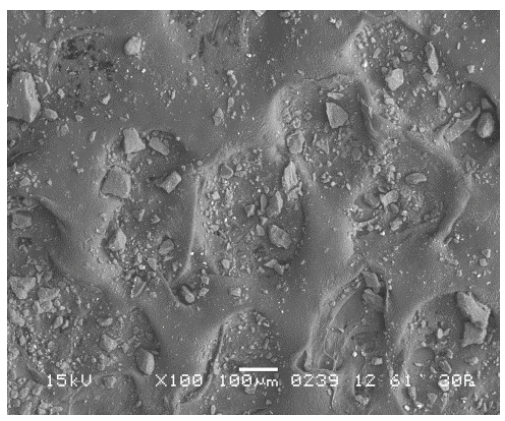

(c)

FIGURE 6: Micrographs of solids: (a) scraped tire, (b) thermal shock, and (c) pyrolysis.

polymorphic polymers (several crystalline structures) as PLA which is detected as double melting peaks that have been proposed [20-22] to arise from $\alpha$ - and $\alpha^{\prime}$-crystalline forms of the polymer. $\alpha^{\prime}$ and $\alpha$ peaks appeared at around 148 and $159^{\circ} \mathrm{C}$, respectively, and a slight diminution in those values was found for concentration of $80 \%$ of PLA and lower. Same trend was observed for $T_{c}$, a displacement to lower value as the concentration of PLA diminishes. It seems that the elastomer from tire slows down the formation and amount of crystals. On the other hand, apparently $T_{g}$ did not exhibit such variation staying at about $58^{\circ} \mathrm{C}$. The TGA results shown in Figure 7(b) exhibited a difference in thermal decomposition influenced by tire concentration, so there was a clear divergence in heat resistance. It is clear that with the augmentation of tire concentration, amount of solid residues will be higher due to the presence of minerals in the tire.

Typical stress-strain curves for PLA/tire blends are presented in Figure 8 and numerical results are in Table 2. PLA

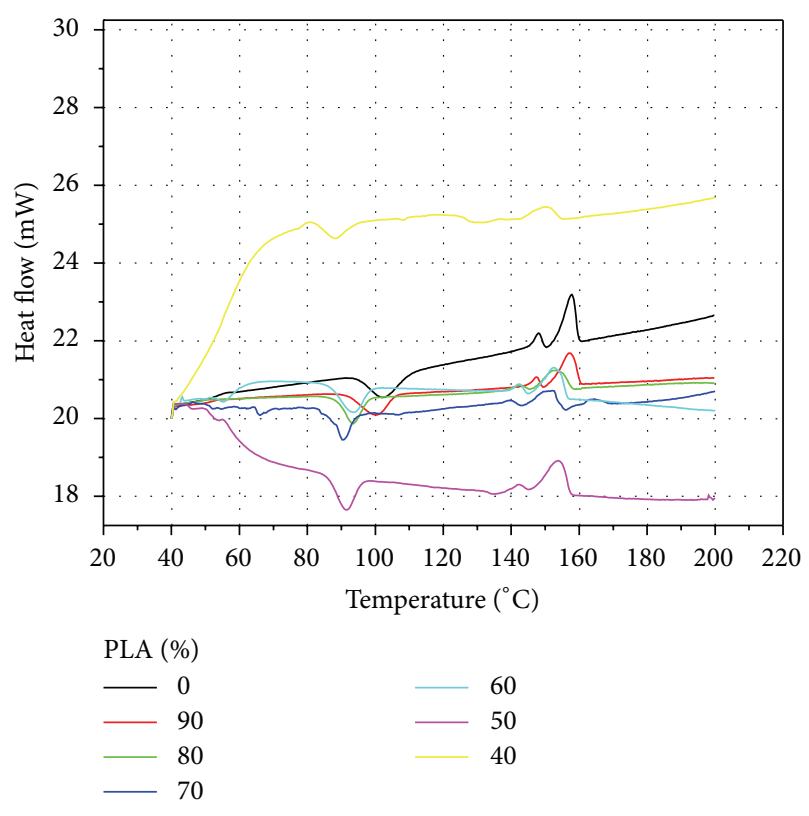

(a)
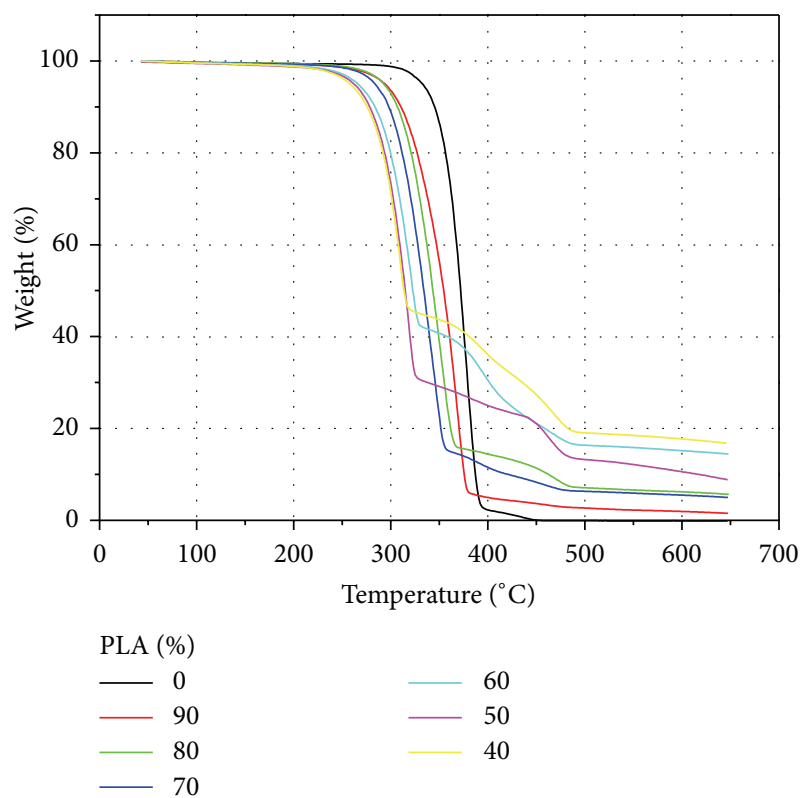

(b)

FIgURE 7: Thermal analyses: (a) DSC and (b) TGA.

TABLE 2: Mechanical properties of composite material.

\begin{tabular}{lccc}
\hline PLA $(\%)$ & Strength $(\mathrm{MPa})$ & Strain $(\%)$ & $E(\mathrm{MPa})$ \\
\hline 100 & 27.6 & 3.2 & 1403.03 \\
90 & 2 & 0.2 & 1249.8 \\
80 & 0.9 & 0.46 & 1181.4 \\
70 & 1.1 & 1.08 & 880.1 \\
60 & 1.0 & 1.7 & 272.6 \\
50 & 0.9 & 2.2 & 218.9 \\
40 & 0.8 & 2.3 & 245.1 \\
\hline
\end{tabular}




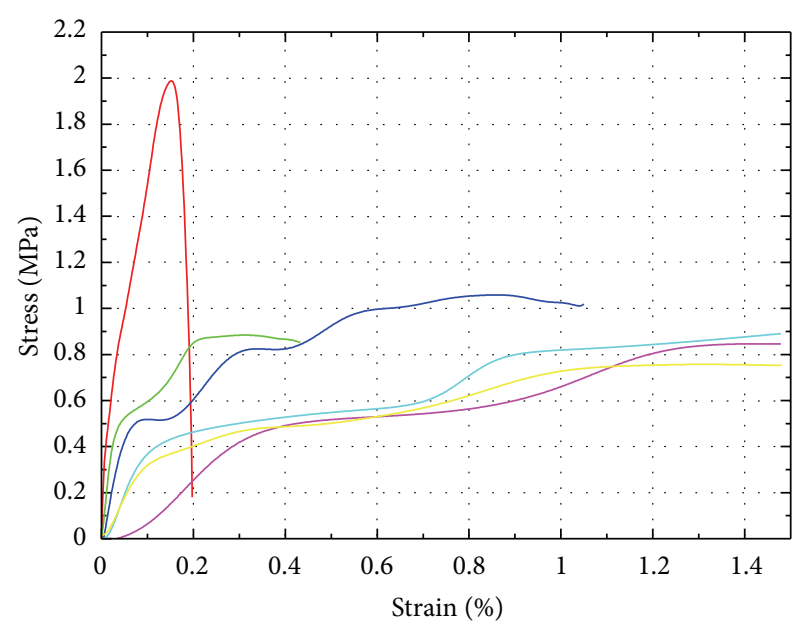

PLA (\%)

$\begin{array}{rr}-90 & -60 \\ -\quad 80 & 50 \\ -70 & 40\end{array}$

FIgURE 8: Tensile properties of PLA/tire blends.

shows tensile strength of $27.6 \mathrm{MPa}$ and modulus of $1403 \mathrm{MPa}$. With the first addition of $10 \mathrm{wt} \%$ of scraped tire, an important decrement of tensile strength $(2 \mathrm{MPa})$ is achieved. Elastic modulus $(E)$ is also reduced but not drastically to $1249 \mathrm{MPa}$. Eventually, with the increment of tire content, the system is governed by a rubber behavior. On the other hand, fracture behavior of the specimens in tensile mode changed from brittle fracture of the neat PLA to ductile fracture of the blends. In previous works [5,23-26] where flexible and tough materials are blended with PLA, a substantial amount of elongation (strain at break $710 \%$ ) is achieved; however, with rubber obtained from tire this behavior is not allowed due to the crosslinked system.

Figure 9 presents results of Izod notch impact tests where it can be seen that, with the first addition of $10 \%$ of elastomeric filler, the impact resistance has a diminution of about $60 \%$ in comparison with PLA; absorbed energy exhibited similar tendency. A gradual enhancement in the impact resistance and absorbed energy is obtained with the increment of tire concentration. Significant variation is found when volume fraction of elastomeric particles reaches $60 \%$ with similar values to virgin PLA.

PLA is similar to many polymers that can undergo plastic flow mechanisms, initiated by dispersed rubber domains. Scraped tire flakes induce energy dissipation mechanisms in the matrix which retard crack initiation and propagation and ultimately result in a material with improved toughness.

The morphology of tensile fracture surfaces was studied by SEM as shown in Figure 10. Photographs at PLA 100\% and $90 \%$ indicate a brittle behavior exhibiting a smooth longitudinal fracture surface without visible plastic deformation. However, at higher concentrations empty spaces as voids are originated by rubber pull-outs at the scanned surface. PLA/tire 40\%-60\% blend had the highest elongation at break, and its matrix experienced plastic deformation in the stress

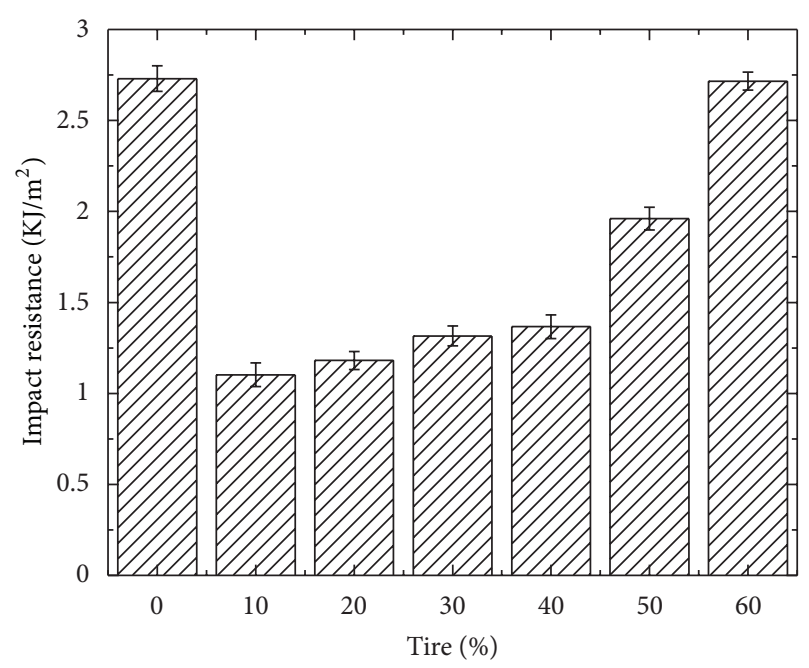

(a)

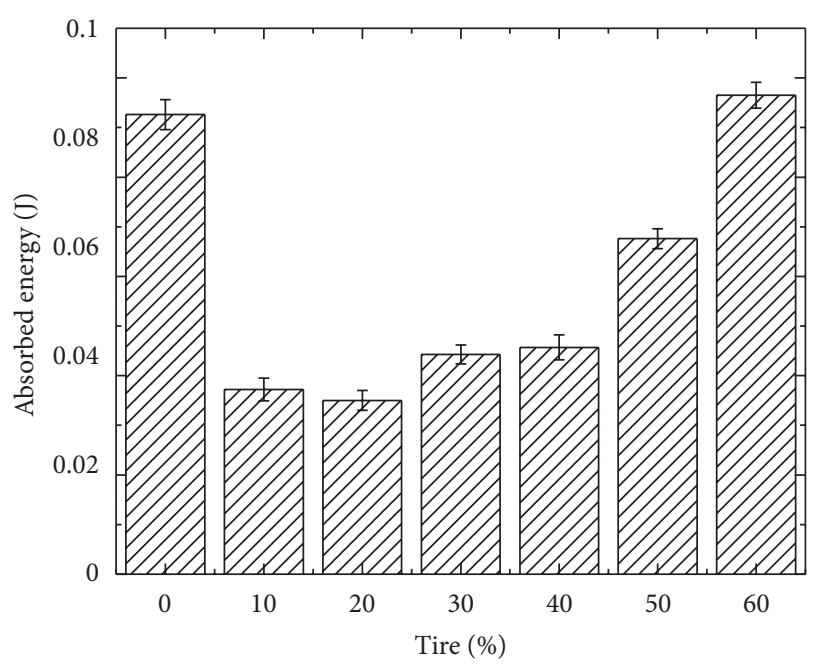

(b)

FIGURE 9: Impact test (a) resistance and (b) absorbed energy.

direction. For lower concentration of tire samples whose elongations are smaller at break, their SEM micrographs evidently suggest the toughening mechanism.

Debonding of the rubber particles from the PLA matrix under tensile stress is clearly observed at higher concentrations of tire. These cavities were formed during tension when the stress was higher than the bonding strength at the interface between the PLA matrix and elastomeric inclusions. Scraped rubber debonds from the PLA matrix at the interface, and so cavities arose. These cavities were enlarged in the stress direction along with the deformation of the matrix. Since rubber has different elastic properties compared with PLA matrix, its particles act as stress concentrators under tensile stress. Although a good dispersion of scraped tire into PLA matrix is observed, it is clear that the adhesion is not strong in any of the composites taken the material to an early ductile fracture. There is evidence of immiscibility between both PLA and the elastomeric material. 


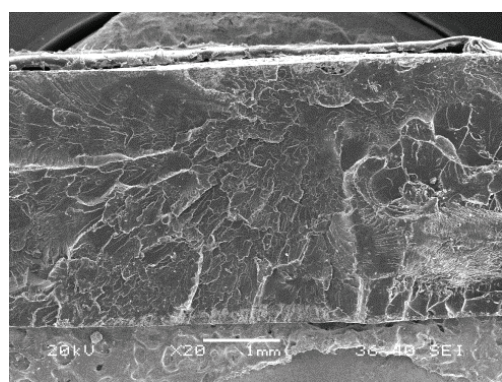

$100 / 0 \%$

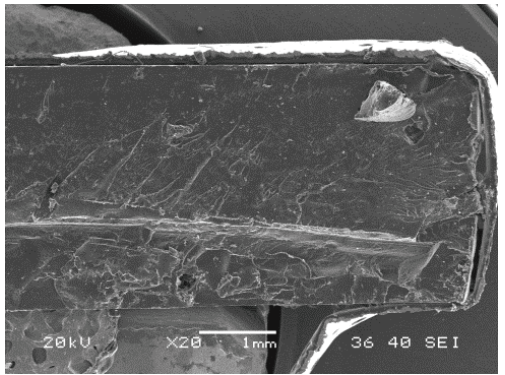

$90 / 10 \%$

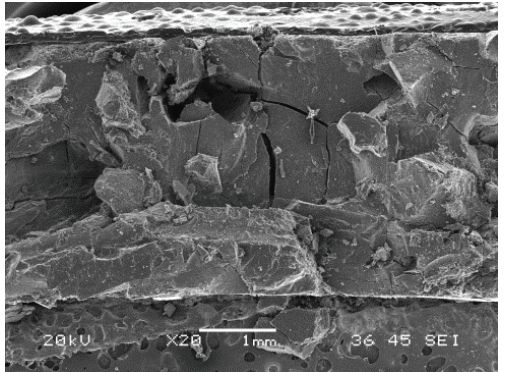

$60 / 40 \%$

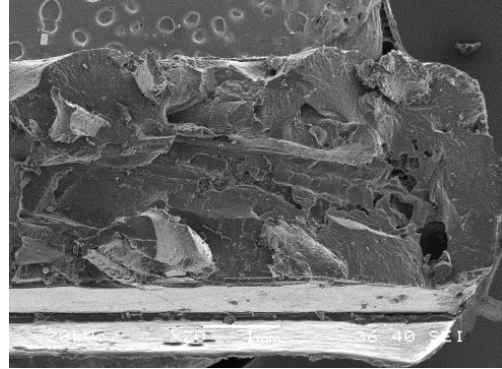

$80 / 20 \%$

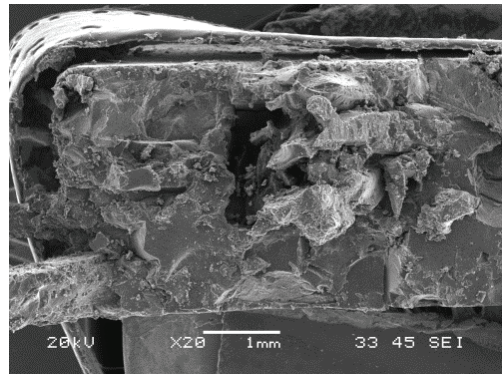

$50 / 50 \%$

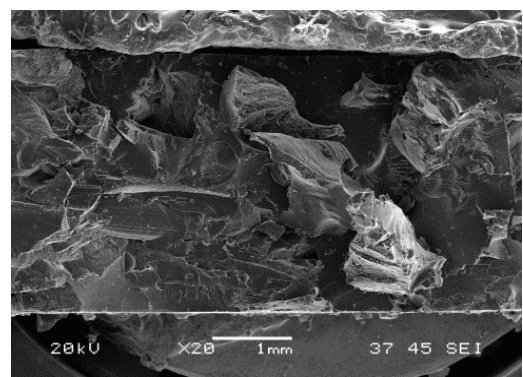

$70 / 30 \%$

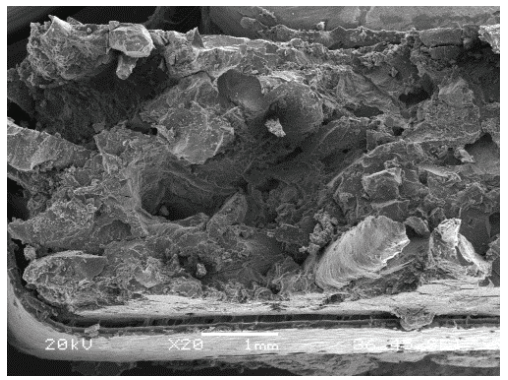

$40 / 60 \%$

FIGURE 10: Fractured surfaces of PLA/tire blends.

\section{Conclusions}

Physicochemical characterization of the solid residues obtained from scraped tires by means of two reduction processes, pyrolysis and thermal shock, was performed in order to compare efficiency and viability of both processes as an option for wasted tires control and to be used as fillers in PLA blends. Differences in components, morphology, and amount of residual solids were found. Scraped tires, in the form of elastomeric flakes, were chosen as filler into PLA matrix. An effect in thermal events in PLA was found to be caused by the increment of elastomeric content in blends. Mechanical properties were found to be affected as well by the addition of filler into PLA. An enhancement in toughness is only obtained at high values of tire concentration equal to virgin PLA values. Finally, it is important to point out some features that can affect the transference of elastic toughness from the rubber to the PLA matrix: the rubber must be distributed as small domains (usually $0.1-1.0 \mu \mathrm{m}$ ) in the matrix polymer and it must have good interfacial adhesion to PLA. SEM micrographs exhibited the poor interfacial adhesion between tire and PLA.

A further investigation has to be done in the interphase level and intent surface modifications in order to augment the adhesion. It is also recommendable to understand the mechanisms of degradation of partially biodegradable materials such as PLA/tire composite in order to understand the environmental factors that affect any possible application.

PLA/tire composites displayed good mechanical performance that makes them a good prospectus for collision and impact applications. A good example for that is the automotive industry, where the application of impact absorbers materials was doubled in the form of different cover parts over the last few years.

\section{Conflict of Interests}

The authors affirm that there is no conflict of interests, and they have no financial support from any company, and the authors do not have a direct financial relation with the commercial identities mentioned in the submitted paper.

\section{Acknowledgment}

The authors are grateful to the Mexican Council for Science and Technology (CONACYT) for the provision of Grant 60204/CM0042. 


\section{References}

[1] N. Ayrilmis, U. Buyuksari, and E. Avci, "Utilization of waste tire rubber in the manufacturing of particleboard," Materials and Manufacturing Processes, vol. 24, no. 6, pp. 688-692, 2009.

[2] O. Martin and L. Avérous, "Plasticization and properties of biodegradable multiphase systems," Polymer, vol. 42, no. 14, pp. 6209-6219, 2001.

[3] A. K. Bledzki, A. Jaszkiewicz, and D. Scherzer, "Mechanical properties of PLA composites with man-made cellulose and abaca fibres," Composites A, vol. 40, no. 4, pp. 404-412, 2009.

[4] N. E. Suyatma, A. Copinet, L. Tighzert, and V. Coma, "Mechanical and barrier properties of biodegradable films made from chitosan and poly (lactic acid) blends," Journal of Polymers and the Environment, vol. 12, no. 1, pp. 1-6, 2004.

[5] L. Jiang, M. P. Wolcott, and J. Zhang, "Study of biodegradable polylactide/poly(butylene adipate-co-terephthalate) blends," Biomacromolecules, vol. 7, no. 1, pp. 199-207, 2006.

[6] L. T. Lim, R. Auras, and M. Rubino, "Processing technologies for poly(lactic acid)," Progress in Polymer Science, vol. 33, pp. 820852,2008

[7] M. Ajioka, K. Enomoto, K. Suzuki, and A. Yamaguchi, "The basic properties of poly(lactic acid) produced by the direct condensation polymerization of lactic acid," Journal of Environmental Polymer Degradation, vol. 3, no. 4, pp. 225-234, 1995.

[8] L. Zhang, S. H. Goh, and S. Y. Lee, "Miscibility and phase behavior of poly(D,L-lactide)/poly-(p-vinylphenol) blends," Journal of Applied Polymer Science, vol. 70, no. 4, pp. 811-816, 1998.

[9] A. J. Nijenhuis, E. Colstee, D. W. Grijpma, and A. J. Pennings, "High molecular weight poly(L-lactide) and poly(ethylene oxide) blends: thermal characterization and physical properties," Polymer, vol. 37, no. 26, pp. 5849-5857, 1996.

[10] A. Mohamed, S. H. Gordon, and G. Biresaw, "Polydactic acid/polystyrene bioblends characterized by thermogravimetric analysis, differential scanning calorimetry, and photoacoustic infrared spectroscopy," Journal of Applied Polymer Science, vol. 106, no. 3, pp. 1689-1696, 2007.

[11] D. Raghavan, H. Huynh, and C. F. Ferraris, "Workability, mechanical properties, and chemical stability of a recycled tyre rubber-filled cementitious composite," Journal of Materials Science, vol. 33, no. 7, pp. 1745-1752, 1998.

[12] F. A. Aisien, F. K. Hymore, and R. O. Ebewele, "Potential application of recycled rubber in oil pollution control," Environmental Monitoring and Assessment, vol. 85, no. 2, pp. 175-190, 2003.

[13] M. Sienkiewicz, J. Kucinska-Lipka, H. Janik, and A. Balas, "Progress in used tyres management in the European Union: a review," Waste Manage, vol. 32, pp. 1742-1751, 2012.

[14] M. Miranda, F. Pinto, I. Gulyurtlu, and I. Cabrita, "Pyrolysis of rubber tyre wastes: a kinetic study," Fuel, vol. 103, pp. 542-552, 2013.

[15] ASTM D882-12 Standard Test Method for Tensile Properties of Thin Plastic Sheeting, American Society for Testing Materials, Philadelphia, Pa, USA.

[16] ASTM D256-10 Standard Test Methods for Determining the Izod Pendulum Impact Resistance of Plastics, American Society for Testing Materials, Philadelphia, Pa, USA.

[17] S. Galvagno, S. Casu, M. Martino, E. Di Palma, and S. Portofino, "Thermal and kinetic study of tyre waste pyrolysis via TG-FTIRMS analysis," Journal of Thermal Analysis and Calorimetry, vol. 88, no. 2, pp. 507-514, 2007.
[18] P. M. Stefani, D. Garcia, J. Lopez, and A. Jimenez, "Thermogravimetric analysis of composites obtained from sintering of rice husk-scrap tire mixtures," Journal of Thermal Analysis and Calorimetry, vol. 81, pp. 315-320, 2005.

[19] R. Mis-Fernandez, J. A. Azamar-Barrios, and C. R. RiosSoberanis, "Characterization of the powder obtained from wasted tires reduced by pyrolysis and thermal shock process," Journal of Applied Research and Technology, vol. 6, pp. 95-104, 2008.

[20] X. Chen, J. Kalish, and S. H. Hsu, "Structure Evolution of a $\alpha$ 'Phase Poly(lactic acid)," Journal of Polymer Science, vol. 49, pp. 1446-1454, 2011

[21] T. Tábi, I. E. Sajó, F. Szabó, A. S. Luyt, and J. G. Kovács, “Crystalline structure of annealed polylactic acid and its relation to processing," eXPRESS Polymer Letters, vol. 4, pp. 659-668, 2010.

[22] X. Cao, A. Mohamed, S. H. Gordon, J. L. Willett, and D. J. Sessa, "DSC study of biodegradable poly(lactic acid) and poly(hydroxy ester ether) blends," Thermochimica Acta, vol. 406, no. 1-2, pp. 115-127, 2003.

[23] T. Semba, K. Kitagawa, U. S. Ishiaku, and H. Hamada, "The effect of crosslinking on the mechanical properties of polylactic acid/polycaprolactone blends," Journal of Applied Polymer Science, vol. 101, no. 3, pp. 1816-1825, 2006.

[24] H. A. Schneider, "Glass transition behavior of compatible polymer blends," Polymer, vol. 30, pp. 771-779, 1989.

[25] M. Shibata, S. Oyamada, S. I. Kobayashi, and D. Yaginuma, "Mechanical properties and biodegradability of green composites based on biodegradable polyesters and lyocell fabric," Journal of Applied Polymer Science, vol. 92, no. 6, pp. 3857-3863, 2004.

[26] R. C. Willemse, A. Speijer, A. E. Langeraar, and A. Posthuma De Boer, "Tensile moduli of co-continuous polymer blends," Polymer, vol. 40, no. 24, pp. 6645-6650, 1999. 

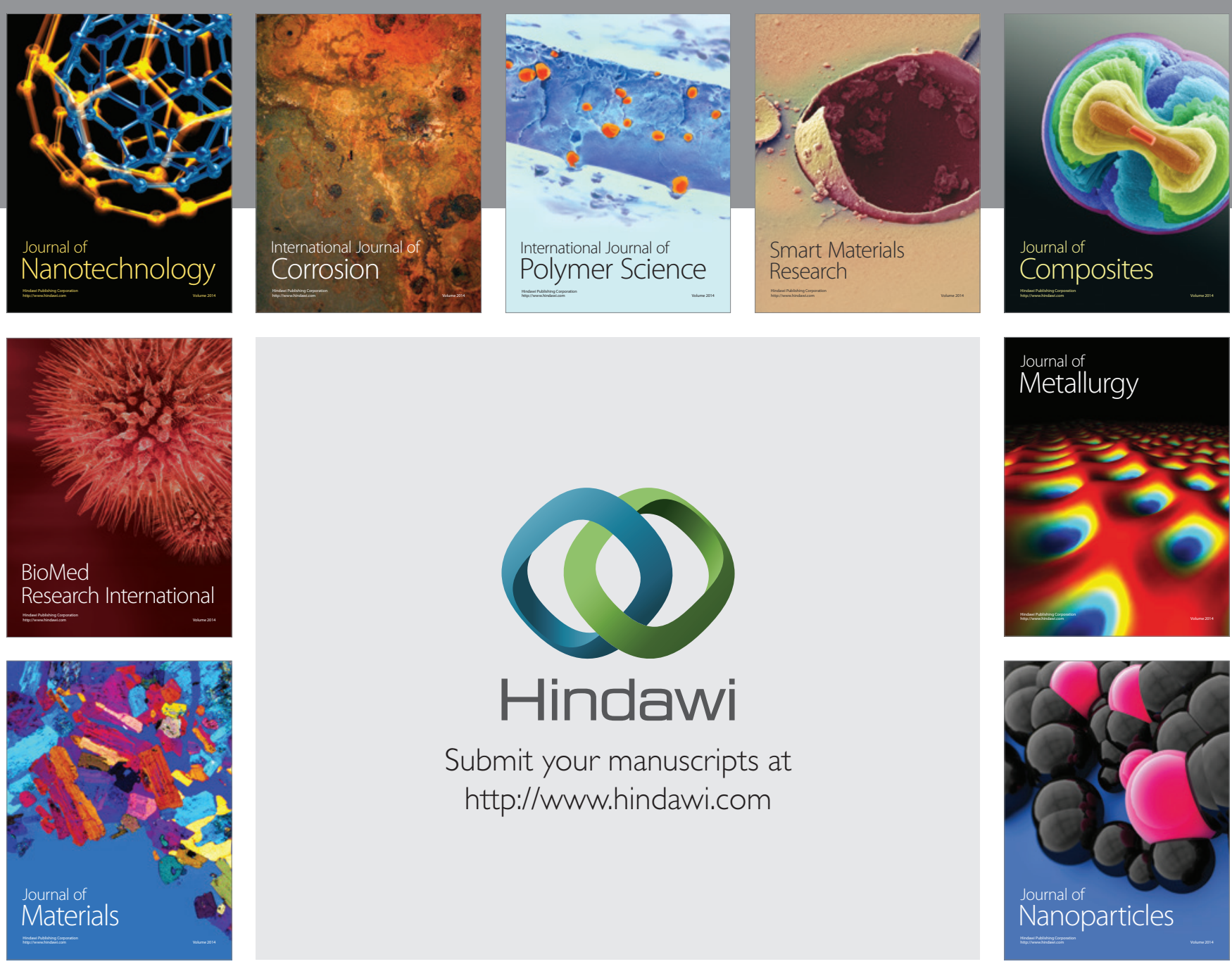

Submit your manuscripts at http://www.hindawi.com
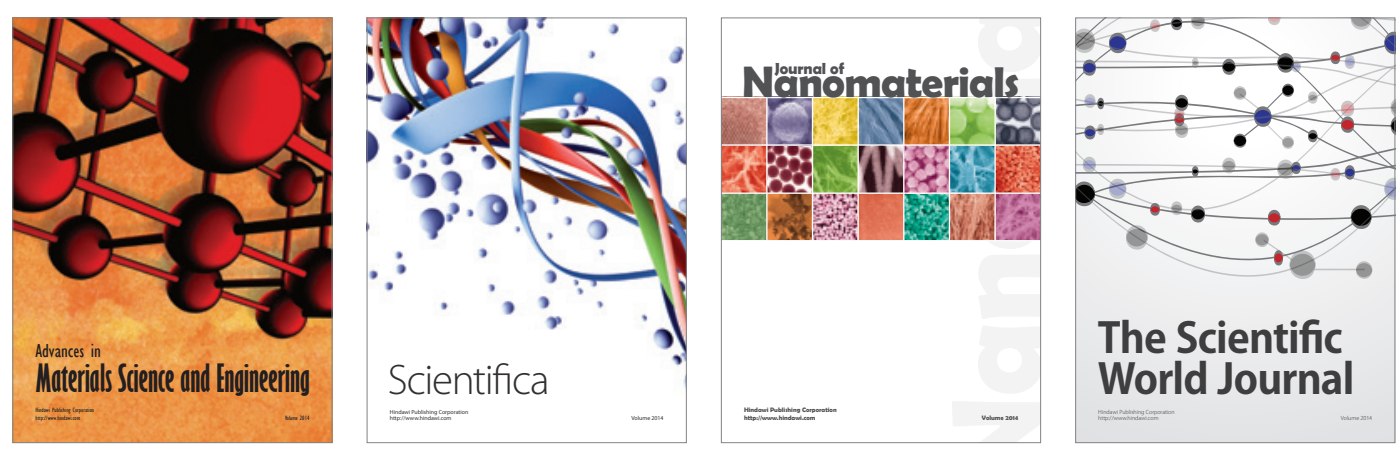

\section{The Scientific World Journal}
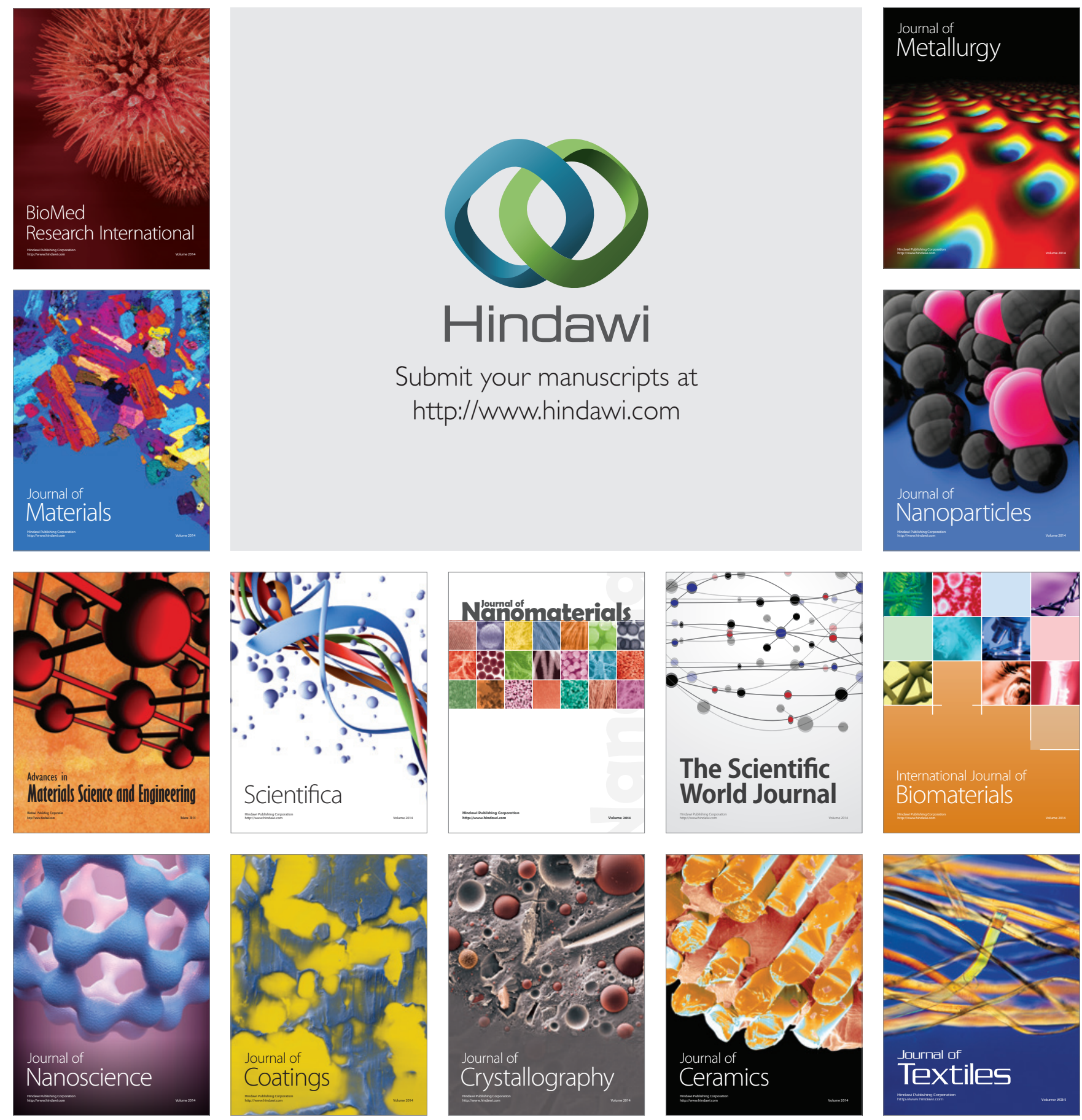